\title{
Monosynaptic Projections of Single Muscle Spindle Afferents to Neck Motoneurons in the Cat
}

\author{
S. A. Keirstead ${ }^{\star}$ and P. K. Rose \\ Department of Physiology, Queen's University, Kingston, Ontario K7L 3N6, Canada
}

\begin{abstract}
Monosynaptic connections to dorsal neck motoneurons of the cat from single afferents supplying primary endings of neck muscle spindles were studied using spike-triggered averaging techniques. Single-fiber EPSPs were detected in only 11 of the 112 afferent-motoneuron pairs examined. The average amplitude of single-fiber EPSPs recorded in motoneurons with a membrane potential of greater than $-40 \mathrm{mV}$ was $49 \mu \mathrm{V}$. Motoneurons receiving functional contacts from a single afferent were confined to a small rostrocaudal zone within the motor nucleus.

The low frequency of single-fiber EPSPs in neck motoneurons could not be attributed to the absence of projections to the ventral horn or to damage to either the afferents or motoneurons. Our results suggest, therefore, that single afferents from neck muscle spindles make functional contacts with a small fraction of neck motoneurons, unlike the arrangement seen in more commonly studied hindlimb muscle systems (Henneman and Mendell, 1981).
\end{abstract}

Flectrophysiological experiments have shown that monosynaptic connections between muscle spindle afferents and motoneurons of the large dorsal neck muscles appear to be weaker than similar connections between hindlimb muscle afferents and their homonymous motoneurons. For example, low-intensity electrical stimulation of neck muscle nerves generally evokes small (average amplitude, $400 \mu \mathrm{V}$ : Rapoport, 1979; range, 350-3100 $\mu \mathrm{V}$ : Brink et al., 1981), usually subthreshold, monosynaptic EPSPs in neck muscle motoneurons (Wilson and Maeda, 1974; Abrahams et al., 1975; Anderson, 1977; Ezure et al., 1978; Rapoport, 1979; Brink et al., 1981). In the analogous situation in the lumbosacral spinal cord, stimulation of the medial gastrocnemius muscle nerve leads to an average monosynaptic EPSP of $4.6 \mathrm{mV}$ in medial gastrocnemius motoneurons (Eccles et al., 1957).

The size of such composite EPSPs will be determined by a combination of several pre- and postsynaptic factors. These include (1) the number of muscle spindle afferents that are activated by electrical stimulation of the muscle nerve, (2) the

\footnotetext{
Received Dec. 28, 1987; revised Feb. 22, 1988; accepted Feb. 26, 1988.

This research was supported by the Canadian Medical Research Council and the Botterell Foundation at Queen's University. S.A.K. was funded by an Ontario Graduate Scholarship. We wish to thank Monica Neuber for excellent technical assistance, S. Lafontaine for assistance in analyzing the data, Wendy Brown for preparation of the manuscript, and Drs. Abrahams, Richmond, and Zarzecki for their comments on earlier versions of the manuscript.

Correspondence should be addressed to Dr. P. K. Rose, Department of Physiology, Queen's University, Botterell Hall, Room 432, Kingston, Untario K7L 3N6, Canada.

a Present address: Neuroscience Unit, Montreal General Hospital, McGill Universily, 1650 Cedar Avenue, Montreal, Quebec, H3G 1A4, Canada.

Copyright (C) 1988 Society for Neuroscience $0270-6474 / 88 / 103945-06 \$ 02.00 / 0$
}

proportion of these afferents that make a functional contact with each motoneuron, and (3) the amplitude of the single-fiber EPSP that individual afferents generate in each motoneuron. When these factors are considered, the relatively small amplitude of EPSPs recorded in neck muscle motoneurons is puzzling. Each of the segmental nerves innervating the large dorsal neck muscles contains 50-80 muscle spindle afferents (Richmond and Abrahams, 1975b; Richmond et al., 1976), which is roughly equivalent to the number of muscle spindles in the hindlimb muscle, medial gastrocnemius (Chin et al., 1962). Furthermore, intra-axonal staining of single afferents supplying primary endings of neck muscle spindles (Keirstead and Rose, 1988) have demonstrated that each afferent gives rise to several collaterals in the segment in which it enters the spinal cord. The collaterals are spaced, on average, $3.3 \mathrm{~mm}$ apart, and each collateral gives rise to an arborization in the ventral horn that extends, on average, for $1400 \mu \mathrm{m}$ in the rostrocaudal plane. Although there are likely to be gaps between the termination zones of adjacent collaterals, the long rostrocaudal spread of dendrites of dorsal neck motoneurons (2-3 mm, Rose, 1981; Keirstead and Rose, 1983) could permit motoneurons whose somata lie in the gaps to be contacted by nearby collaterals. Thus, our morphological data suggest that each afferent could potentially contact the majority of the motoneurons in the same segment as its dorsal root entry, an arrangement commonly seen in the lumbosacral spinal cord (for a review, see Henneman and Mendell, 1981). Singlefiber EPSPs evoked by individual afferents should therefore be small in order to explain the small composite EPSPs observed in response to muscle nerve stimulation.

The present experiments were designed to evaluate the contribution of individual neck muscle spindle afferents to the monosynaptic connection with neck motoneurons using spiketriggered averaging techniques (cf. Mendell and Henneman, 1971). Our results indicate that, contrary to our expectations, single afferents make functional contacts with a very small proportion of the motoneurons innervating dorsal neck muscles. Preliminary accounts of some of the results of this study have been reported previously (Keirstead and Rose, 1984; Rose and Keirstead, 1986).

\section{Materials and Methods}

Experiments were conducted on adult cats, anesthetized with sodium pentobarbital (Somnotol, MTC; $35 \mathrm{mg} / \mathrm{kg}$, ip). All surgical procedures were identical to those used in a previous study of the morphology of afferents originating from primary endings of neck muscle spindles (Kcirstead and Rose, 1988). The cats were paralyzed with gallamine triethiodide (Flaxedil, Poulens; $2.5-5.0 \mathrm{mg} / \mathrm{kg} / \mathrm{hr}$ ) and artificially respirated. During paralysis, the depth of anesthesia was monitored by observing pupil diameter. Normally the pupils were tightly constricted. If the pupils dilated and showed evidence of a reflex constriction to 


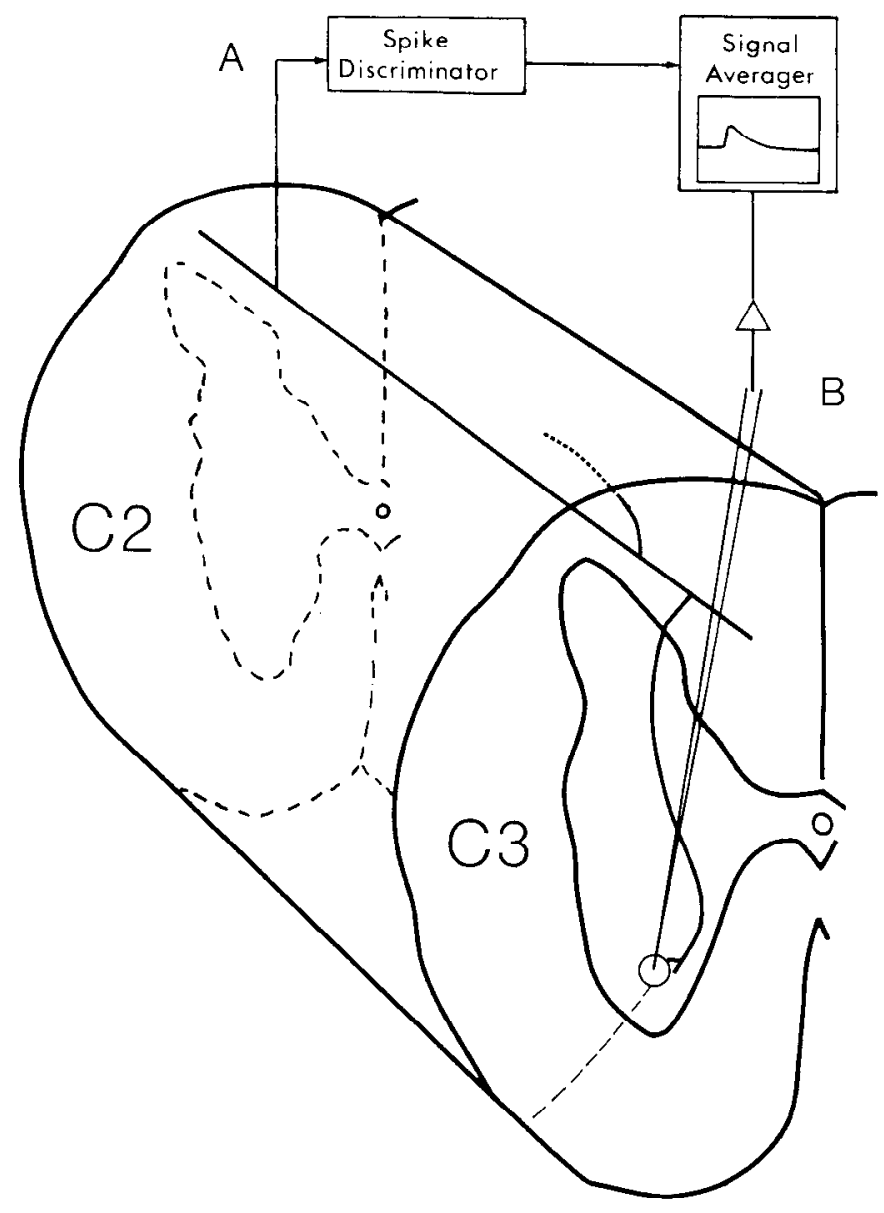

Figure 1. Recording arrangement. Single afferents were recorded extracellularly near the junction of $\mathrm{C}_{1} 1$ and $\mathrm{C} 2(A)$. The membrane potentials of neck motoneurons located in the caudal part of $\mathrm{C} 2$ or throughout C3 were recorded $(B)$ and used as the input to a signal averager that was triggered by afferent activity.

bright light, additional doses $(5 \mathrm{mg} / \mathrm{kg}$ ) of sodium pentobarbital were administered intravenously. The supplementary anesthetic caused the pupils to constrict and the reflex to light was lost.

The spontaneous activity of single neck muscle spindle afferents supplying biventer cervicis (BC), complexus (CM), and splenius (SP) was recorded extracellularly with a tungsten microelectrode in the dorsal funiculus, near the $\mathrm{C} 1 / \mathrm{C} 2$ border, just medial to the dorsal root entry zone (Fig. 1). The nerves supplying $\mathrm{BC}$ and $\mathrm{CM}$ travel together in the C2, C3, and C4 dorsal rami (Richmond and Abrahams, 1975a; Abrahams et al., 1984). The C3 nerves supplying BC and CM were separated and placed on separate stimulating electrodes. However, the $\mathrm{C} 2$ and $\mathrm{C} 4$ nerves to $\mathrm{BC}$ and $\mathrm{CM}$ are difficult to scparate and henec they were not stimulated individually. $\mathrm{BC}$ and $\mathrm{CM}$ afferents travelling in the $\mathrm{C} 2$ and $\mathrm{C} 4$ nerves were therefore referred to as BCCM afferents. Single afferents were identified by their latency and the stimulus intensity required to evoke a response. Spike amplitude, latency, and stimulus threshold were continuously monitored to ensure correct identification of each afferent. Stable extracellular recordings from single afferents could usually be maintained for $1-3 \mathrm{hr}$.

A detailed account of the methods used to distinguish afferents innervating primary endings of neck muscle spindles from other receptors has been previously described (Keirstead and Rose, 1988). Briefly, axons were considered to innervate primary endings of neck muscle spindles if (1) they were excited directly by stimulation of a neck muscle nerve, (2) they were tonically active when the muscles were at or below resting length, and (3) their instantaneous discharge frequency varied by $6 \%$ or more of the mean frequency when the muscles were at or below resting length. All of the afferents described in the present study fulfilled these criteria. Although these criteria are less comprehensive than those usually employed to distinguish primary and secondary endings (Matthews,

\begin{tabular}{llllll}
\hline Table 1. Projection frequency & & & \\
& \\
Motoneuron & & & \\
\cline { 2 - 6 } Afferent & C2 SP & C3 SP & C2 BCCM & C3 BC & C3 CM \\
\hline C2 SP & $0 / 26$ & $0 / 5$ & & & \\
C3 SP & $1 / 3$ & $8 / 26$ & & & \\
C2 BCCM & & & $0 / 1$ & & \\
C3 BC & & $0 / 1$ & $0 / 5$ & $2 / 27$ & \\
C3 CM & & & & $0 / 10$ & $0 / 1$ \\
C4 BCCM & & & & $0 / 8$ & \\
\end{tabular}

Afferents were classified according to the segment in which they entered the spinal cord (e.g., C3) and their origin (e.g., BC). Motoneurons were classified by their segmental location (e.g., C2) and the muscle they supplied (e.g., SP).

${ }^{a}$ Number of single-fiber EPSPs/number of afferent motoneuron pairs examined.

1972), more extensive manipulation of the neck muscles was precluded by the proximity of the recording electrode to the neck muscles themselves. Moreover, the use of these criteria reliably distinguishes between afferents innervating primary endings of muscle spindles and other types of receptors in neck muscles (cf. Richmond and Abrahams, 1979; Keirstead and Rose, 1988).

Intracellular recordings were made using glass micropipettes filled with $2.5 \mathrm{M}$ potassium acetate. The electrodes were beveled to yield tips of 1-2 $\mu \mathrm{m}$, and these electrodes had initial DC resistances of 2-5 M . Motoneurons were impaled in the caudal part of $\mathrm{C} 2$ and throughout $\mathrm{C} 3$ and were excited antidromically by stimulation of $\mathrm{C} 2$ or $\mathrm{C} 3$ nerves innervating $\mathrm{BC}, \mathrm{CM}$, or SP. A low-gain DC display and digital voltmeter were used to monitor resting membrane potential. High-gain $\mathrm{AC}$ recordings (bandpass $1 \mathrm{~Hz}-10 \mathrm{kHz}$ ) of motoneuron membrane potential were stored on magnetic tape with an FM recorder (Racal-Thermionic). A record of the muscle spindle afferent activity was stored simultaneously on a second channel of the tape recorder. A spike discriminator (WP Instruments) was used to generate a brief pulse, one for every action potential, which triggered a signal averager (Neurolog NL 750 or Nicolet 1070) to sample 10 - to 25 -msec-long records of motoneuron membrane potential. Since the afferents were recorded near the $C 1 / C .2$ border, the recorded action potentials could occur later than, or at the same time, as the action potential arrived at the motoneuron pool in the caudal part of $\mathrm{C} 2$ or in $\mathrm{C} 3$. Consequently, the motoneuron membrane potential record was delayed by $1.25-5.0 \mathrm{msec}$ using an analog delay unit (Neurolog NL 740) before being led to the signal averager (see Kirkwood and Sears, 1980). One thousand and twenty-four sequential records were averaged in 4 groups of 256 responses. Calibration pulses of $10 \mu \mathrm{V}$, superimposed on records of motoneuron membrane potential, were readily distinguished using this averaging procedure. Extracellular records (1024) were taken immediately adjacent to the motoneuron and were averaged using the same procedure. A hard copy of the averaged responses was obtained using an $x-y$ plotter (Hewlett Packard). Measurements of latencies, $10-90 \%$ rise times, and amplitudes of the averaged EPSPs were obtained from these records. No attempt was made to correct for the effects of synchronous afferent activity on the amplitude and rise time of single-fiber EPSPs. However, based on the studies of Hamm et al. (1985), it is unlikely that estimates of amplitude and rise time are overestimated by more than $5 \mu \mathrm{V}$ and $0.06 \mathrm{msec}$, respectively.

\section{Results}

Spike-triggered averaging was performed on 112 afferent-moloneuron pairs (40 afferents and 111 motoneurons). In 97 of the 112 pairs the motoneuron's resting membrane potential was greater than or equal to $-40 \mathrm{mV}$, while in the remaining 15 pairs the resting membrane potential was between -22 and -39 $\mathrm{mV}$. All 112 pairs were included in the analysis of functional connectivity, however, since EPSPs were easily distinguished in 2 motoneurons whose membrane potentials, throughout the penetration, were -22 and $-30 \mathrm{mV}$, respectively. In addition, spike-triggered averaging was repeated several times on one afferent-motoneuron pair as the membrane potential of the motoneuron deteriorated from -54 to $-25 \mathrm{mV}$. Although the 
A
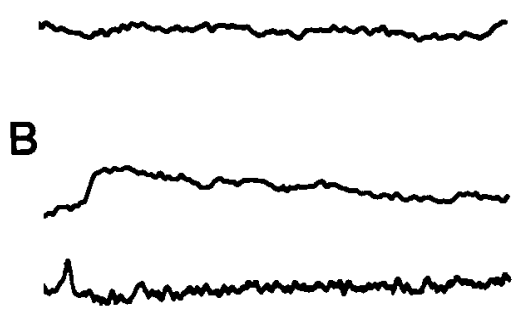

C

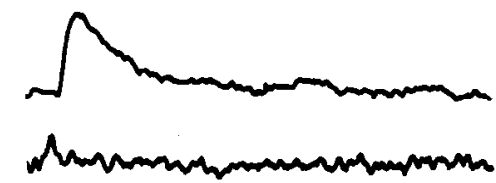

D

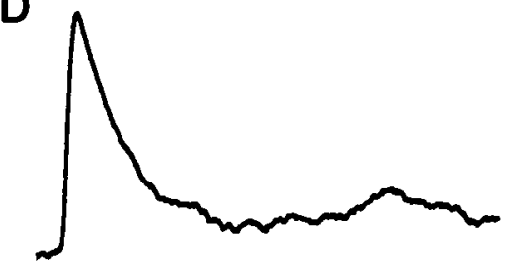

E

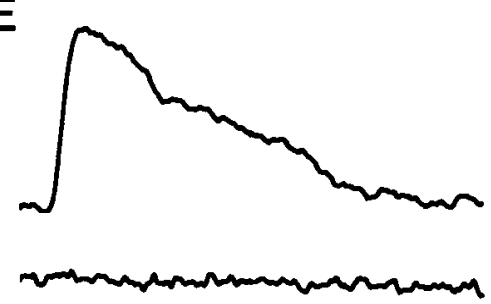

$\mathbf{F}$

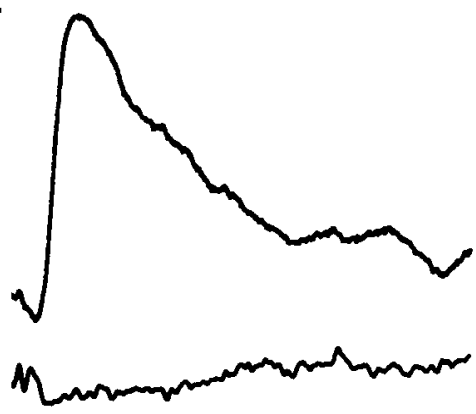

G

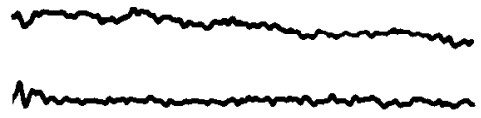

$$
\begin{aligned}
& 20 \mu \mathrm{V} \\
& 10 \mu \mathrm{V}
\end{aligned}
$$

Figure 2. Examples of single-fiber potentials recorded in neck motoneurons. The upper traces are intracellular records (scale bar, $20 \mu \mathrm{V}$ in $A-F$, $10 \mu \mathrm{V}$ in $G$ ) and the lower traces (in $B, C, E, F$, and $G$ ) are extracellular records (scale bar, $10 \mu \mathrm{V}$ ). $A$, Example of the membrane potential of a motoneuron triggered by an afferent whose activity failed to elicit a detectable single-fiber EPSP. Membrane potential, $-60 \mathrm{mV}$. $B$, Single-fiber EPSP recorded in the same motoneuron as shown in $A$ while triggering from a different afferent. Membrane potential, $-50 \mathrm{mV}$. This was the smallest single-fiber EPSP detected. Note the presence of a terminal potential in the extracellular recording. $C$, Single-fiber EPSP recorded in another motoneuron while triggering from the same afferent used in $B$. Membrane potential, $-58 \mathrm{mV}$. $D$. Single-fiber EPSP with a fast rise time and decay. There was no evidence of an axonal, terminal, or focal potential in the extracellular recording (not shown). Membrane potential, $-76 \mathrm{mV}$. $E$, Single-fiber EPSP with a slower rise time and decay. Membrane potential, $-68 \mathrm{mV}$. $F$, Single-fiber EPSP with a focal synaptic potential recorded extracellularly. This was the largest single-fiber EPSP recorded. Membrane potential, $-53 \mathrm{mV}$. $G$, Axonal potential recorded intracellularly and extracellularly. There was no detectable single-fiber EPSP in this motoneuron. Membrane potential, $-68 \mathrm{mV}$.

amplitude of the single-fiber EPSP decreased from 69 to $39 \mu \mathrm{V}$, there was no difficulty in distinguishing the EPSP at membrane potentials of -25 to $-35 \mathrm{mV}$.

Single-fiber EPSPs were recorded in only 11 of the $112(9 /$ 97 , resting membrane potential greater than $-40 \mathrm{mV}$ ) neck muscle afferent-motoneuron pairs examined (Table 1). These EPSPs were evoked by the activity of 5 afferents. In all, 21 afferent-motoneuron pairs were examined using the activity of these afferents as the triggering signal. The relatively high frequency of single-fiber EPSPs in C3 SP motoneurons, triggered by activity in C3 SP afferents (8/26, Table 1$)$, was largely a consequence of the connections of one afferent that evoked single-fiber EPSPs in 5 of 10 SP motoneurons (Afferent 5, Fig. 3).

In 65 motoneurons in which a single-fiber EPSPs could not be detected by spike-triggered averaging, the composite monosynaptic EPSP was examined by electrically stimulating one or more muscle nerve branches. If the afferent axon was in the same nerve branch as that of the motoneuron, the nerve was stimulated below threshold for antidromic invasion. Otherwise, the stimulus to the nerve branch containing the afferent was at least 4 times threshold for extrafusal muscle contraction (as determined before paralysis). Composite monosynaptic EPSPs, ranging from 40 to $3120 \mu \mathrm{V}$ in amplitude, were observed in all but 5 motoneurons.

The single-fiber EPSPs recorded in neck muscle motoneurons had amplitudes ranging from 13 to $85 \mu \mathrm{V}$ (mean, $49 \mu \mathrm{V}, n=$ 9 , resting membrane potential $>40 \mathrm{mV}$ ). The rise time of singlefiber EPSPs varied from 0.25 to $0.89 \mathrm{msec}$. The half-width was difficult to determine as most single-fiber EPSPs were small and some did not decay smoothly. There was occasionally a discrete hump or plateau which appeared to be superimposed on the falling phase (Fig. $2 E$ ). Terminal potentials-small positivenegative field potentials (see Munson and Sypert, 1979) - were not recorded intracellularly in association with single-fiber EPSPs, but axonal potentials - small negative field potentials $(n=5$; see Munson and Sypert, 1979) - and terminal potentials $(n=$ 3 ) were recorded at sites just extracellular to 8 of the 11 motoneurons in which single-fiber EPSPs were recorded (Fig. 2). The latency from the positive peak of the terminal potential to the onset of the single fiber EPSP was $0.33,0.45$ and $0.64 \mathrm{msec}$, respectively. Single-fiber focal synaptic potentials (cf. Munson and Sypert, 1979) were rare $(n=2)$. One focal synaptic potential was recorded just extracellular to one of the motoneurons in which a single-fiber EPSP was detected (Fig. $2 F$ ). The other focal synaptic potential (amplitude, $11 \mu \mathrm{V}$; duration, $8.5 \mathrm{msec}$ ) was associated with a terminal potential. However, the afferent recording was lost before any intracellular recordings could be made. Axonal potentials were only detected on 4 occasions in regions where single-fiber EPSPs were not observed. In 3 of these cases, axonal polentials were recorded both intracellularly and extracellularly (Fig. $2 G$ ).

Motoneurons in which single-fiber EPSPs were recorded were not distributed evenly within the motoneuron nuclei. In 10 cases, recordings were made in 4 to 11 motoneurons while triggering from a single afferent. These motoneurons were spread over a distance of 775 to $2700 \mu \mathrm{m}$ in the longitudinal plane. In 8 instances, no EPSPs were recorded in any of the motoneurons (e.g., Fig. 3, afferents 1, 2, 3). When a single-fiber EPSP was detected, as in the remaining 2 cases (Fig. 3, afferents 4 and 5), adjacent motoneurons had single-fiber EPSPs. While triggering 


\section{$\mathrm{R} \longrightarrow \mathrm{C}$}

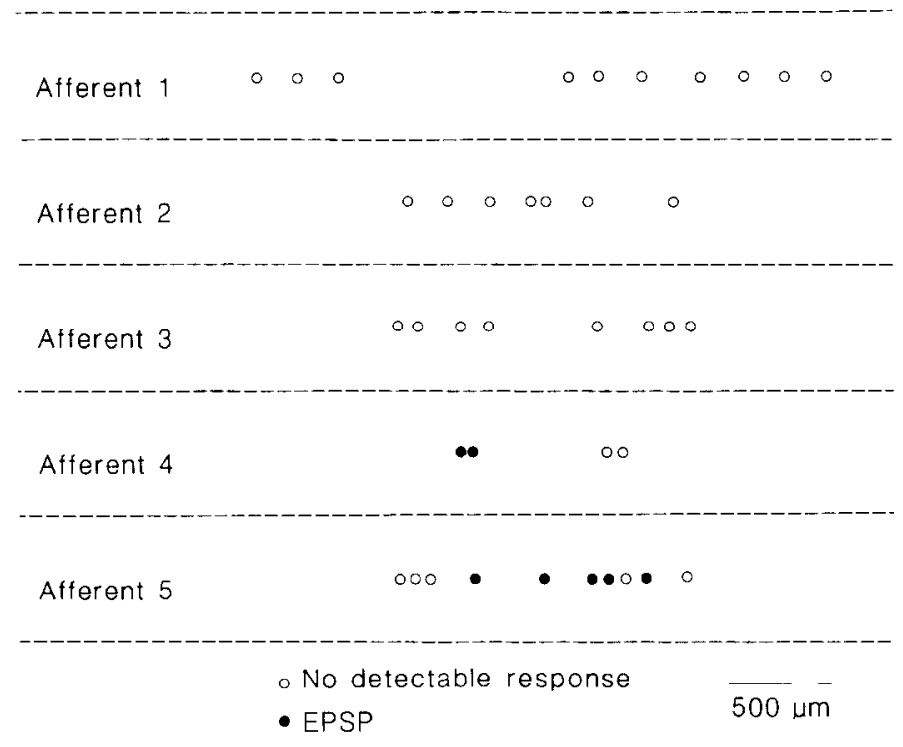

Figure 3. Examples of the rostrocaudal positions of motoneurons from which recordings were made while triggering from individual afferents. $R$, rostral; $C$, caudal.

from afferent 5, single-fiber EPSPs were recorded in 5 of 6 motoneurons that were confined to an $800-\mu \mathrm{m}$-long zone. Singlefiber EPSPs were not recorded in motoneurons located rostral or caudal to this region. In those cases in which a single-fiber EPSP was recorded in only one motoneuron, the afferent was lost before neighboring motoneurons could be studied. Thus, the rostrocaudal extent of the single afferent's effects could not be determined.

\section{Discussion}

The results of this study indicate that single afferents innervating primary endings of neck muscle spindles make functional contacts with a small proportion (overall, 10\%) of neck muscle motoneurons. In light of this very low percentage of connectivity, especially in comparison with the data obtained in similar studies on Ia-motoneuron connectivity in hindlimb muscles (Henneman and Mendell, 1981), it is necessary to consider the possibility that the present study has yielded an artificially low estimate of the projection frequency of single neck muscle afferents. Ihere are several reasons to believe that this is not the case.

In the present expcriments, afferent activity was recorded in the dorsal funiculus in the rostral part of $\mathrm{C} 2$. This site is at least several millimeters rostral to the location of the motoneurons studied, as well as the level at which most afferents entered the spinal cord (see Fig. 1). Thus, the afferent recording electrode could not produce a conduction block in the afferent between the recording site and the motoneurons (see also Harrison and Taylor, 1981).

It is also unlikely that membrane damage due to electrode impalement could significantly reduce the percentage of motoneurons with detectable EPSPs. In agreement with Watt et al. (1976), we found that the amplitude of single-fiber EPSPs decreases as the motoneuron membrane potential deteriorates. Nevertheless, these EPSPs are still easily detected. The functional integrity of impaled motoneurons was further substantiated by the fact that composite EPSPs were evoked in response to muscle nerve stimulation in 60 of 65 motoneurons in which single-fiber EPSPs were not detected. In addition, we rarely recorded axonal and terminal potentials, except near motoneurons in which a single-fiber EPSP was recorded. These potentials are recorded extracellularly, and they do not depend on the integrity of the motoneuron. All of these observations suggest that the absence of detectable single-fiber EPSPs was more likely to be due to the absence of a functional conncction than to an inability of the postsynaptic motoneuron to generate a detectable EPSP.

Although the projection frequency of single neck afferents from spindle primaries to neck motoneurons is very low compared with that of hindlimb muscle spindle afferents to their homonymous motoneurons, this feature is not a unique characteristic of afferents from dorsal neck muscles. For example, Appenteng et al. (1978) recorded small (mean amplitude, 18 $\mu \mathrm{V}$ ) single-fiber EPSPs in 14 of 91 recordings from motoneurons supplying jaw elevator muscles of the cat. These investigators attributed the low frequency of single-fiber EPSPs to the localized projection of single afferents to small regions of the motor nucleus (see also Appenteng et al., 1985). Other studies have shown that muscle spindles lying in muscles involved in lateral jaw movements also project to a small percentage of their homonymous motoneurons (11 of 32 afferent motoneuron pairs: Nozaki et al., 1985). The external intercostal muscle system represents a less extreme case in which single primarylike muscle spindle afferents project to $42-48 \%$ of ipsisegmental external intercostal motoneurons (Kirkwood and Sears, 1982a). Thus, although there is comparatively little information about the spinal projections of muscle spindle afferents in muscle systems other than those of the hindlimb, the available information suggests that the projections to motoneurons are not governed by a single set of rules.

As described in the introductory remarks, we had anticipated that each afferent would contact a large fraction of the motoneurons in an individual nucleus. The low percentage of connectivity that we have observed could be explained in at least 2 ways. Obviously, if many boutons of each collateral contact neurons other than motoneurons (for possible target neurons, see Keirstead and Rose, 1988), there would be fewer boutons available to contact motoneurons. It is equally possible that most of the contacts are on neck motoneurons, but that many of the contacts are "nonfunctional." Several recent studies have demonstrated that the probability of release at single Ia afferent boutons in the lumbosacral spinal cord can be as low as zero (Edwards et al., 1976; Hirst et al., 1981; Jack et al., 1981; Redman and Walmslcy, 1983; Henncman ct al., 1984).

Clamann et al. (1985) have demonstrated that the projection frequency of hindlimb Ia afferents onto hindlimb motoneurons is related to 3 factors: the conduction velocity of the afferent, the conduction velocity of the motoneuron, and the distance between the spinal entry point of the afferent and the location of the motoneuron. The conduction velocity of afferents from primary endings of neck muscle spindles are lower (average 55 $\mathrm{m} / \mathrm{sec}$ : Richmond and Abrahams, 1979) than similar hindlimb afferents, but hindlimb spindle afferents with conduction velocities in the range of 50-60 m/sec make functional contacts with approximately $50 \%$ of homonymous motoneurons (Clamann et al., 1985). We did not examine the effect of motoneuron axon size and the distance between individual motoneurons and the points at which the afferents entered the spinal cord. However, the projection frequency of hindlimb afferents is at least 
$50 \%$ for motoneurons with slow conduction velocities located more than $2 \mathrm{~mm}$ from the sites at which the afferents entered the spinal cord (Clamann et al., 1985). Thus, the known relationship between percentage of connectivity and properties of either the afferents or motoneurons do not fully explain the low projection frequency of neck muscle spindle afferents to their homonymous motoneurons.

The amplitudes of single-fiber FPSPs recorded in neck motoneurons were typically smaller than seen in hindlimb motoneurons (average amplitude, 49 vs. $\sim 100 \mu \mathrm{V}$ : Henneman and Mendell, 1981). This feature, together with the low projection frequency of single afferents, suggests that monosynaptic connections of afferents from primary endings of neck muscle spindles to dorsal neck motoneurons have a minor role in the control of head movement. This conclusion may be premature. The amplitude of single-fiber EPSPs recorded in hindlimb motoneurons is not fixed but varies with the frequency of afferent activity and the previous history of afferent activity (Hirst et al., 1981; Luscher et al., 1983; Honig et al., 1983; Davis et al., 1985). Thus, under some circumstances, the amplitude of single-fiber EPSPs in neck motoneurons may be greater than our averaged records imply. Furthcrmorc, the small amplitude of single-fiber EPSPs recorded in jaw motoneurons and the low projection frequency of jaw muscle afferents suggest that these connections are also functionally weak. Yet excitation of jaw muscle spindles evokes a powerful monosynaptic stretch reflex and can contribute significantly to the regulation of jaw muscle stiffness (Lamarre and Lund, 1975; Goodwin et al., 1978). Similarly, the apparently weak monosynaptic connections of spindle afferents to external intercostal motoneurons can increase motoneuron activity if the motoneuron is tonically active (Kirkwood and Sears, 1982b). Finally, neck motoneurons that receive functional contacts from single neck muscle afferents appear to be arranged in clusters. Since collaterals from single neck muscle afferents are widely spaced (Keirstead and Rose, 1988), each cluster may be the result of a selective functional projection of a single collateral. As a consequence, a single neck muscle afferent would project to several separate groups of motoneurons located along the rostrocaudal axis of the motoneuron nucleus. The position of each motoneuron group would correspond approximately to the position of the collaterals from individual neck muscle afferents. Dorsal neck muscles have an unusually complex architecture and are composed of several, in series, compartments, some of which can be further divided into smallcr subcompartments based on their innervation (Brink et al., 1981; Richmond et al., 1985; Armstrong et al., 1988). Thus, the discontinuous and localized projection of single neck muscle afferents may reflect the demands of an unusually complex muscle architecture where motoneurons in a single cluster innervate muscle fibers in the same compartment and motoneurons in adjacent clusters innervate functionally related, in series, muscle compartments.

\section{References}

Abrahams, V. C., F. Richmond, and P. K. Rose (1975) Absence of monosynaptic reflex in dorsal neck muscles of the cat. Brain Res. 92: 130-131.

Abrahams, V. C., B. Lynn, and F. J. R. Richmond (1984) Organization and sensory properties of small myelinated fibres in the dorsal cervical rami of the cat. J. Physiol. (Lond.) 347: 177-187.

Anderson, M. E. (1977) Segmental reflex inputs to motoneurons innervating dorsal neck musculature in the cat. Exp. Brain Res. 28: 175-187.
Appenteng, K., M. J. O'Donovan, G. Somjen, J. A. Stephens, and A. Taylor (1978) The projection of jaw elevator muscle spindle afferents to fifth nerve motoneurones in the cat. J. Physiol. (Lond.) 279. $409-423$.

Appenteng, K., R. Donga, and R. G. Williams (1985) Morphological and electrophysiological determination of the projections of jaw-elcvator muscle spindle afferents in rats. J. Physiol. (Lond.) 369: 93113.

Armstrong, J. B., P. K. Rose, S. Vanner, G. J. Bakker, and F. J. R. Richmond (1988) Compartmentalization of motor units in the cat neck muscle, biventer cervicis. J. Neurophysiol. 60: 30-45.

Brink, E. E., K. Jinnai, and V. J. Wilson (1981) Pattern of segmental monosynaptic input to cat dorsal neck motoneurons. J. Neurophysiol. 46: 496-505.

Chin, N. K., M. Cope, and M. Pang (1962) Number and distribution of spindle capsules in seven hindlimb muscles of the cat. In Symposium on Muscle Receptors, D. Barker, ed., pp. 241-248, University Press, Hong Kong.

Clamann, H. P., E. Henneman, H. R. Luscher, and J. Mathis (1985) Structural and topographical influences on functional connectivity in spinal monosynaptic reflex arcs in the cat. J. Physiol. (Lond.) 358: 483-507.

Davis, B. M., W. F. Collins, and L. M. Mendell (1985) Potentiation of transmission at Ia-motoneuron connections induced by repeated short bursts of afferent activity. J. Neurophysiol. 54: 1541-1552.

Eccles, J. C., R. M. Eccles, and A. Lundberg (1957) The convergence of monosynaptic excitatory afferents on to many different species of alpha motoneurons. J. Physiol. (Lond.) 137: 22-50.

Edwards, F. R., S. J. Redman, and B. Walmsley (1976) Statistical fluctuations in charge transfer at Ia synapses on spinal motoneurons. J. Physiol. (Lond.) 259: 665-688.

Ezure, K., S. Sasaki, Y. Uchino, and V. J. Wilson (1978) Frequencyresponse analysis of vestibular-induced neck reflex in cat. II. Functional significance of cervical afferents and polysynaptic descending pathways. J. Neurophysiol. 41: 459-471.

Goodwin, G. M., D. Hoffman, and E. S. Luschei (1978) The strength of the reflex response to sinusoidal stretch of monkey jaw closing muscles during voluntary contraction. J. Physiol. (Lond.) 279: 81111.

Hamm, T. M., R. M. Reinking, D. D. Roscoe, and D. G. Stuart (1985) Synchronous afferent discharge from a passive muscle of the cat: Significance for interpreting spike-triggered averages. J. Physiol. (Lond.) 365: 77-102.

Harrison, P. J., and A. Taylor (1981) Individual excitatory post-synaptic potentials due to muscle spindle Ia afferents in cat triceps surae motoneurones. J. Physiol. (Lond.) 312: 455-470.

Henneman, E., and L. M. Mendell (1981) Functional organization of motoneuron pool and its inputs. In Handbook of Physiology, Sect. 1, Vol. 2, The Nervous System, V. E. Brooks, cd., pp. 423-507, American Physiological Society, Bethesda, MD.

Henneman, E., H. R. Luscher, and J. Mathis (1984) Simultaneously active and inactive synapses of single Ia fibres on cat spinal motoneurones. J. Physiol. (Lond.) 352: 147-161.

Hirst, G. D. S., S. J. Redman, and K. Wong (1981) Post-tetanic potentiation and facilitation of synaptic potentials evoked in cat spinal motoneurons. J. Physiol. (Lond.) 321: 97-109.

Honig, M. G., W. F. Collins, and L. M. Mendell (1983) $\alpha$-motoneuron EPSPs exhibit different frequency sensitivities to single Ia-afferent fiber stimulation. J. Neurophysiol. 49: 886-901.

Jack, J. J. B., S. J. Redman, and K. Wong (1981) Modifications to synaptic transmission at group Ia synapses on cat spinal motoneurones by 4-aminopyridine. J. Physiol. (Lond.) 321: 111-126.

Keirstead, S. A., and P. K. Rose (1983) Dendritic distribution of splenius motoneurons in the cat: Comparison of motoneurons innervating different regions of the muscle. J. Comp. Neurol. 219:273284.

Keirstead, S. A., and P. K. Rose (1984) An examination of muscle spindle afferent motoneuron connectivity in the upper cervical spinal cord. Can. J. Physiol. Pharmacol. 62: AXVII.

Keirstead, S. A., and P. K. Rose (1988) Structure of the intraspinal projections of single, identified muscle spindle afferents from neck muscles of the cat. J. Neurosci. (in press).

Kirkwood, P. A., and T. A. Sears (1980) The measurement of synaptic connections in the mammalian nervous system by means of spike triggered averaging. In Progress in Clinical Neurophysiology, Vol. 8 , 
Spinal and Supraspinal Mechanisms of Voluntary Motor Control and Locomotion, J. E. Desmedt, ed., pp. 44-71, Karger, Basel.

Kirkwood, P. A., and T. A. Sears (1982a) Excitatory post-synaptic potentials from single muscle spindlc afferents in external intercostal motoneurones of the cat. J. Physiol. (Lond.) 322: 287-314.

Kirkwood, P. A., and T. A. Sears (1982b) The effects of single afferent impulses on the probability of firing of external intercostal motoneurones in the cat. J. Physiol. (Lond.) 322: 315-336.

Lamarre, Y., and J. P. Lund (1975) Load compensation in human masseter muscles. J. Physiol. (Lond.) 253: 21-35.

Luscher, H.-R., P. W. Ruenzel, and E. Henneman (1983) Effects of impulse frequency, PTP, and temperature on responses elicited in large populations of motoneurons by impulses in single Ia fibers. J. Neurophysiol. 50: 1045-1058.

Matthews, P. B. C. (1972) Mammalian Muscle Receptors and Their Central Actions. Arnold, London.

Mendell, L., and E. Henneman (1971) Terminals of single Ia fibers: Location, density, and distribution within a pool of 300 homonymous motoneurons. J. Neurophysiol. 34: 171-187.

Munson, J. B., and G. W. Sypert (1979) Properties of single central Ia afferent fibres projecting to motoneurones. J. Physiol. (Lond.) 296: 315-327.

Nozaki, S., A. Iriki, and Y. Nakamura (1985) Trigeminal mesencephalic neurons innervating functionally identified muscle spindles and involved in the monosynaptic stretch reflex of the lateral pterygoid muscle of the guinea pig. J. Comp. Neurol. 236: 106-120.

Rapoport, S. R. (1979) Reflex connexions of motoneurones of muscles involved in head movement in the cat. J. Physiol. (Lond.) 289: 311327.

Redman, S., and B. Walmsley (1983) Amplitude fluctuations in syn- aptic potentials evoked in cat spinal motoneurones at identified group Ia synapses. J. Physiol. (Lond.) 343: 135-145.

Richmond, F. J. R., and V. C. Abrahams (1975a) Morphology and enzyme histochemistry of dorsal muscles of the cat neck. J. Neurophysiol. 38: 1312-1321.

Richmond, F. J. R., and V. C. Abrahams (1975b) Morphology and distribution of muscle spindles in dorsal muscles of the cat neck. $J$. Neurophysiol. 38: 1322-1339.

Richmond, F. J. R., and V. C. Abrahams (1979) Physiological properties of muscle spindles in dorsal neck muscles of the cat. J. Neurophysiol. 42: 604-617.

Richmond, F. J. R., G. C. B. Anstee, E. A. Sherwin and V. C. Abrahams (1976) Motor and sensory fibers of neck muscle nerves in the cat. Can. J. Physiol. Pharmacol. 54: 254-304.

Richmond, F. J. R., D. R. R. MacGillis, and D. A. Scott (1985) Musclefiber compartmentalization in cat splenius muscles. J. Neurophysiol. 53: $868-885$.

Rose, P. K. (1981) Distribution of dendrites from biventer cervicis and complexus motoneurons stained intracellularly with horseradish peroxidase in the adult cat. J. Comp. Neurol. 197: 395-409.

Rose, P. K., and S. A. Keirstead (1986) Segmental projection from muscle spindles: A perspective from the upper cervical spinal cord Can. J. Physiol. Pharmacol. 64: 505-508.

Watt, D. G. D., E. K. Stauffer, A. Taylor, R. M. Reinking, and D. G. Stuart (1976) Analysis of muscle receptor connections by spiketriggered averaging. I. Spindle primary and tendon organ afferents. J Neurophysiol. 39: 1375-1392.

Wilson, V. J., and M. Maeda (1974) Connections between semicircular canals and neck motoneurons in the cat. J. Neurophysiol. $37: 346-$ 357. 